\title{
TRIM52 regulates the proliferation and invasiveness of lung cancer cells via the Wnt/ß-catenin pathway
}

\author{
XIAOYAN MU, HEGEN LI*, LEI ZHOU* and WEIJIE XU* \\ Department of Oncology, Longhua Hospital, Shanghai University of Traditional Chinese Medicine, \\ Shanghai 200032, P.R. China
}

Received July 12, 2018; Accepted March 4, 2019

DOI: $10.3892 / o r .2019 .7110$

\begin{abstract}
As a major cause of cancer-associated mortalities, lung cancer is frequently diagnosed in males and females with an incidence ratio of 2.1:1. Tripartite motif 52 (TRIM52), an E3 ubiquitin ligase, has been reported to be involved in various biological functions, including cell proliferation and invasiveness. In the present study, an elevated TRIM52 level was observed in tumor tissues of patients with lung cancer and in lung cancer cell lines. The downregulation of TRIM52 in lung cancer cells significantly suppressed the proliferation of lung cancer cells, arrested the cell cycle at the G1 phase and was accompanied by a decrease in the levels of $\beta$-catenin, proliferating cell nuclear antigen, c-Myc and Cyclin D1 proteins. Additionally, TRIM52-induced cell proliferation and invasiveness, as well as the levels of cell cycle-associated proteins, were completely counteracted by the Wnt/ $\beta$-catenin inhibitor XAV939. Based on these data, it was speculated that TRIM52 is critical for lung cancer progression and that downregulation of TRIM52 could inhibit cell proliferation by blocking cell cycle progression. It was also speculated that TRIM52 upregulation promotes proliferation and invasiveness through activation of the Wnt/ $\beta$-catenin pathway. Thus, TRIM52 has the potential to be a therapeutic target for lung cancer.
\end{abstract}

\section{Introduction}

As the leading cause of cancer-associated mortalities globally, lung cancer is frequently diagnosed in males and females with an incidence ratio of $\sim 2.1: 1$ in $2008(1,2)$. In 2008, 1.4 million people globally succumbed to lung cancer, which represented $18 \%$ of all cancer-associated mortalities (3). Generally, lung

Correspondence to: Dr Xiaoyan Mu, Department of Oncology, Longhua Hospital, Shanghai University of Traditional Chinese Medicine, 725 Wan Ping Nan Road, Shanghai 200032, P.R. China

E-mail: muxiaoyan1983_lhzl@126.com

*Contributed equally

Key words: tripartite motif 52, lung cancer, cell proliferation, cell cycle, invasion, Wnt/ $\beta$-catenin pathway cancer is classified into two main types: Small cell lung cancer (SCLC); or non-SCLC (NSCLC) (4,5). Accumulating evidence has revealed that tobacco smoking is a major cause of lung cancer, as it is associated with $~ 90 \%$ of all lung cancer diagnoses (6-9). Furthermore, smokers have a 10 -fold increased probability of developing lung cancer, compared with nonsmokers (10).

The Wnt/ $\beta$-catenin pathway has been indicated to serve important roles in a number of cancer types. For example, it has been reported that the metastatic behavior of lung cancer cell lines is increased by increased $\mathrm{Wnt} / \beta$-catenin signaling in vitro (11). A previous study demonstrated that Wnt family genes are frequently upregulated in multiple human cancer types, including NSCLC $(12,13)$. Through $\beta$-catenin, oncogenic Wnt signaling is transduced. Wnt signaling promotes the accumulation of $\beta$-catenin, and elevated $\beta$-catenin translocates to the nucleus where it forms complexes with transcription factors (14). This in turn stimulates the expression of Wnt target molecules, including the oncogenes Cyclin D1 and c-Myc $(15,16)$.

Tripartite motif-containing (TRIM) family proteins, with $>80$ members, contain three conserved domains, RING, B-box and a coiled-coil region, and are regarded as E3 ubiquitin ligases that are associated with human diseases, including intracellular immunity and cancer (17-20). It has been reported that TRIM proteins regulate multiple biological processes, including cell proliferation and invasion (21-23). Studies demonstrated an association between TRIM 24 and TRIM29, and the progression of solid tumors $(24,25)$. Elevated TRIM65 has also been observed in lung cancer, where it facilitates the growth of tumors $(26,27)$; whereas, TRIM31 was reported to be downregulated in NSCLC, which indicates that it may function as a tumor suppressor (28). TRIM52 is a novel TRIM protein that contains only a unique expanded RING domain and a B-box 2 domain (29). Previous studies demonstrated that TRIM52 could promote cell proliferation, migration and invasion in hepatocellular carcinoma through ubiquitination $(30,31)$. Another study indicated that TRIM52 acts as an oncogene in ovarian cancer, where it is associated with the nuclear factor- $\kappa \mathrm{B}$ pathway (32). However, the effect of TRIM52 in lung cancer remains largely unknown.

In the present study, a high expression of TRIM52 was observed in tumor tissues of patients with lung cancer and in lung cancer cell lines. The downregulation of TRIM52 
in lung cancer cell lines significantly inhibited cell proliferation by blocking cell cycle progression, which occurred concurrently with decreases in $\beta$-catenin, proliferating cell nuclear antigen (PCNA), c-Myc and Cyclin D1 expression. Furthermore, TRIM52-induced cell proliferation and invasion were completely counteracted by the Wnt/ $\beta$-catenin inhibitor XAV939. These results indicated that TRIM52 downregulation inhibits lung cancer progression, possibly through inactivation of the Wnt/ $\beta$-catenin signaling pathway.

\section{Materials and methods}

Tumor and adjacent normal tissues of patients with lung cancer. Following informed consent being obtained, 43 pairs of tumor and paracancer tissues from 43 patients with lung cancer treated at Longhua Hospital (Shanghai, China) were collected and immediately frozen in liquid nitrogen at $-196^{\circ} \mathrm{C}$. After the tissues were sectioned at $5 \mu \mathrm{m}$, the expression of TRIM52 was detected by immunohistochemistry, according to the subsequent protocol. All experiments in the present study were approved by the Ethics Committee of Shanghai University of Traditional Chinese Medicine (Shanghai, China).

Cell culture. A total of 5 cell lines derived from human lung cancer (H1975, H466, A549, H358 and H1299), and a cell line derived from the pulmonary epithelium (16HBE) were purchased from the Cell Bank of the Chinese Academy of Science (Shanghai, China). These cells were cultured in a $5 \% \mathrm{CO}_{2}$ humidified-incubator at $37^{\circ} \mathrm{C}$ (Thermo Forma 3111; Thermo Fisher Scientific, Inc., Waltham, MA, USA) with RPMI-1640 medium (cat. no. SH30809.01B; HyClone; GE Healthcare Life Sciences; Logan, UT, USA) supplemented with $10 \%$ fetal bovine serum (cat. no. 16000-044; Gibco; Thermo Fisher Scientific, Inc.) and 1\% antibiotic (x100; a mixture of penicillin and streptomycin; cat. no. P1400-100; Beijing Solarbio Science \& Technology Co., Ltd., Shanghai, China). During incubation, the medium was replaced with fresh RPMI-1640 medium every two days according to cellular demand until the experiments. After selecting, three cell lines, H358, H1299 and H1975, were used for subsequent experiments.

Lentiviral construction. Short hairpin RNA (shRNA) sequences targeted to the TRIM52 gene (NM_032765.3) were synthesized and double strand-annealed to form the shRNA construct. The shRNA construct was inserted into Agel I/Ecol I restriction sites of a pLKO.1-puro vector (Addgene, Inc., Cambridge, MA, USA). Subsequently, the 894 bp full-length coding DNA sequence region of TRIM52 containing the EcoR I/BamH I restriction sites was synthesized by Genewiz, Inc. (Shanghai, China) and was then inserted into EcoRI/BamHI restriction sites of a pLVX-Puro vector (Clontech Laboratories, Inc., Mountainview, CA, USA). pLKO.1-shTRIM52 and pLVX-Puro-TRIM52 were confirmed by DNA sequencing (Shanghai Meiji Biomedical Technology Co., Ltd., Shanghai, China). Subsequently, $0.5 \mu \mathrm{g}$ core plasmid of pLKO.1-shTRIM52 or pLVX-Puro-TRIM52 and $1.5 \mu \mathrm{g}$ mixed viral packaging plasmids psPAX2 and $\mathrm{pMD} 2 \mathrm{G}$ (Addgene, Inc.) were added to $250 \mu \mathrm{l}$ serum-free RPMI-1640 medium, and $9 \mu 1$ Lipofectamine ${ }^{\circledR} 2000$ (Invitrogen; Thermo
Fisher Scientific, Inc.) was added into a serum-free RPMI-1640 medium with a total volume of $250 \mu \mathrm{l}$, and then the two were mixed and transfected into 293 T cells. The virus particles were obtained after $48 \mathrm{~h}$ of transfection.

Experimental grouping. In vitro, to regulate the expression of TRIM52 in lung cancer cell lines, lentivirus-mediated RNA interference or overexpression was used. H358 or H1299 cells were infected with RPMI-1640 medium (control), pLKO.1-puro vector (negative control lentivirus; shNC), or shTRIM52 lentivirus (shTRIM52-1, shTRIM52-2, shTRIM52-3 and shTRIM52-4), while H1975 cells were infected with RPMI-1640 medium (control), pLVX-Puro vector (Clontech Laboratories, Inc.) or TRIM52 recombinant lentivirus (oeTRIM52). After $48 \mathrm{~h}$, the efficiency of knockdown or overexpression was detected by reverse transcription-quantitative polymerase chain reaction (RT-qPCR) and western blotting, according to the subsequent protocols. shTRIM52-1, shTRIM52-4 and oeTRIM52 lentiviruses were used for subsequent experiments.

Furthermore, H358 or H1299 cells were infected with RPMI-1640 medium, shNC, shTRIM52-1 or shTRIM52-4, and H1975 cells were treated with vector, oeTRIM52, Vector $+20 \mu \mathrm{M}$ XAV939 (Wnt/ $\beta$-catenin inhibitor; S1180; Selleck Chemicals, Shanghai, China) or oeTRIM52 $+20 \mu \mathrm{M}$ XAV939. Assays to determine proliferation and cell cycle, and western blot analysis were then performed.

Immunohistochemistry. Following paraffin embedding, the tissue slides were fixed for $48 \mathrm{~h}$ in $10 \%$ formalin at $4^{\circ} \mathrm{C}$ and then cut into $5 \mu \mathrm{m}$ thick sections, which were baked at a constant temperature in an oven at $65^{\circ} \mathrm{C}$ for $30 \mathrm{~min}$, and then deparaffinized in two changes of xylenes (Sinopharm Chemical Reagent Co., Ltd., Shanghai, China) for $15 \mathrm{~min}$ each. The deparaffinized sections were then rehydrated in 100, 95, 85 and $75 \%$ ethanol solutions for 5 min each, which was followed by washing once in tap water for $10 \mathrm{~min}$. Following antigen retrieval with $0.01 \mathrm{M}$ sodium citrate buffer $\left(\mathrm{pH}\right.$ 6.0) at $\sim 95^{\circ} \mathrm{C}$ for $15 \mathrm{~min}$, the slides were incubated with $0.3 \% \mathrm{H}_{2} \mathrm{O}_{2}$ for $10 \mathrm{~min}$ at room temperature in a humidified chamber and washed with $0.02 \mathrm{M}$ phosphate-buffered saline (PBS). Subsequently, the slides were incubated with a rabbit antibody against TRIM52 (dilution 1:500; cat. no. NBP2-31651; Novus Biologicals, LLC, Littleton, CO, USA) at room temperature for $1 \mathrm{~h}$ in a humidified chamber. The slides were then incubated with a horseradish peroxidase-labeled broad-spectrum secondary antibody (dilution 1:1,000; cat. no. D-3004; Shanghai Long Island Biotechnology Co., Ltd., Shanghai, China) at room temperature for $25 \mathrm{~min}$. At room temperature, following DAB staining for 5 min, a washing with tap water, (cat. no. FL-6001; Shanghai Long Island Biotechnology Co., Ltd.), the sections were stained with hematoxylin (cat. no. 714094; Zhuhai BASO Biotechnology Co., Ltd., Zhuhai, China) for $3 \mathrm{~min}$ at room temperature, exposed to $1 \%$ hydrochloric acid-alcohol at room temperature for $3 \mathrm{sec}$ for differentiation and flushed with tap water once for $10 \mathrm{~min}$. After drying, mounting and cover-slipping, the slides were imaged by an upright light microscope at x200 magnification (ECLIPSE Ni; Nikon Corporation, Tokyo, Japan) and were analyzed by an IMS image analysis system (DS-Ri2; Nikon Corporation). 
$R T$-qPCR. RT-qPCR was performed to detect the TRIM52 mRNA level in cells. The total RNA in cells (H1975, H466, A549, H358 and H1299) that were or were not treated with lentiviruses was extracted by TRIzol ${ }^{\circledR}$ reagent (cat. no. 1596-026; Invitrogen; Thermo Fisher Scientific, Inc.), and following quantification, the integrity of the RNA was confirmed by $1 \%$ agarose gel electrophoresis. The extracted RNA was reversed transcribed into cDNA using a Reverse Transcription kit (cat. no. K1622; Fermentas; Thermo Fisher Scientific, Inc.). With cDNA used as a template and a SYBR ${ }^{\circledR}$-Green PCR kit (cat.no. K0223; Thermo Fisher Scientific, Inc.), RT-qPCR reactions were performed in an ABI 7300 Real-Time PCR system (ABI-7300; Applied Biosystems; Thermo Fisher Scientific, Inc.). The expression of TRIM52 mRNA normalized to GAPDH was analyzed by ABI Prism 7300 SDS software $1.4 \mathrm{v}$ (Applied Biosystems; Thermo Fisher Scientific, Inc.) and was calculated using the $2^{-\Delta \Delta \mathrm{Cq}}$ method (33). The primer sequences were as follows: TRIM52, forward, 5'-GTGCCATCTGCT TGGATTAC-3', and reverse, 5'-TCATCT TCCTCCTCG TTCTG-3', and GAPDH, forward, 5'-AATCCCATCACC ATCTTC-3', and reverse, 5'-AGGCTGTTGTCATACTTC-3'. The RT-qPCR reaction conditions were as follows: $95^{\circ} \mathrm{C}$ for $10 \mathrm{~min} ; 95^{\circ} \mathrm{C}$ for $15 \mathrm{sec}$ and $60^{\circ} \mathrm{C}$ for $45 \mathrm{sec}$ for 40 cycles; $95^{\circ} \mathrm{C}$ for $15 \mathrm{sec} ; 60^{\circ} \mathrm{C}$ for $1 \mathrm{~min} ; 95^{\circ} \mathrm{C}$ for $15 \mathrm{sec}$; and $60^{\circ} \mathrm{C}$ for $15 \sec (34)$.

Western blot analysis. Total proteins were extracted from lentivirus-treated H358, H1299 or H1975 cells by radioimmunoprecipitation assay buffer (Beijing Solarbio Science \& Technology Co., Ltd.; R0010), which contained protease and phosphatase inhibitors, and were quantified by a Bicinchoninic Assay quantification kit (Thermo Fisher Scientific, Inc.; PICPI23223). Approximately $25 \mu \mathrm{g}$ of proteins was separated by $10 \%$ SDS-PAGE (JRDUN Biotechnology Co., Ltd, Shanghai), followed by a semi-dry transfer onto polyvinylidene fluoride membranes (cat. no. HATF00010; EMD Millipore, Billerica, MA, USA) by electroblotting. After $1 \mathrm{~h}$ of blocking in 5\% skim milk at room temperature (cat. no. BYL40422; BD Biosciences; Becton, Dickinson and Company, Franklin Lakes, NJ, USA), the blots were incubated with primary antibodies against TRIM52 (1:200; cat. no. sc-135589; Santa Cruz Biotechnology, Inc., Dallas, TX, USA), $\beta$-catenin $(1: 5,000$; cat. no. ab32572; Abcam, Cambridge, UK), PCNA (1:1,000; cat. no. ab29; Abcam), c-Myc (1:1,000; cat. no. ab32072; Abcam), Cyclin D1 (1:5,000; cat. no. ab134175; Abcam) and $\beta$-actin (1:1,000; cat. no. 4970; Cell Signaling Technology, Inc., Danvers, MA, USA) with gentle shaking at $4^{\circ} \mathrm{C}$ overnight. Following the incubation with the horseradish peroxidase-conjugated secondary antibodies goat anti-rabbit (cat. no. A0208), donkey anti-goat (cat. no. A0181), and goat anti-mouse (cat. no. A0216) (1:1,000; Beyotime Institute of Biotechnology, Shanghai, China) for $1 \mathrm{~h}$ at $37^{\circ} \mathrm{C}$, the blots were incubated with chemiluminescent detection reagent (cat. no. WBKLS0100; EMD Millipore) for $5 \mathrm{~min}$ in the dark. Bound proteins were then visualized using an Enhanced Chemiluminescent imaging system (Tanon-5200; Tanon Science and Technology Co., Ltd., Shanghai, China). Finally, using $\beta$-actin as the loading control, the relative protein levels were calculated by ImageJ software $1.47 \mathrm{v}$ (National Institutes of Health, Bethesda, MD, USA).
Proliferation assay. H358, H1299 or H1975 cells in a logarithmic growth phase were digested by $0.25 \%$ trypsin (Beijing Solarbio Science \& Technology Co., Ltd.; P1300-100) and counted under a optical microscope at x10 magnification (cat. no. XDS-500C; Shanghai Cai Kang Optical Instrument Co., Ltd., Shanghai, China) to prepare a cell suspension of $3 \times 10^{4}$ cells $/ \mathrm{ml}$. Subsequently, $100 \mu \mathrm{l}$ of each cell suspension was inoculated in 96-well culture plates (cat. no. TR4001; TrueLine, Romeoville, IL, USA) in triplicate and cultured overnight at $37^{\circ} \mathrm{C}$ in a humidified $5 \% \mathrm{CO}_{2}$ incubator. After $0,24,48$ and $72 \mathrm{~h}$ of treatment according to the experimental grouping, Cell Counting Kit-8 (CCK-8; cat. no. CP002; Signalway Antibody, College Park, MD, USA) reagent and serum-free RPMI-1640 medium were mixed at a volume ratio of 1:10, and $100 \mu \mathrm{l}$ of the mixture was added to each well. The plates were incubated for $1 \mathrm{~h}$ at $37^{\circ} \mathrm{C}$ in a $5 \% \mathrm{CO}_{2}$ incubator. Using a microplate reader (cat. no. DNM-9602; Beijing Pulang New Technology Co., Ltd., Beijing, China), the absorbance value (optical density) at $450 \mathrm{~nm}$ was measured.

Cell cycle detection. Following treatment, according to the experimental grouping, H358, H1299 or H1975 cells were collected and centrifuged for $5 \mathrm{~min}$ at $1,000 \mathrm{x} \mathrm{g}$ at room temperature and were then resuspended in $300 \mu \mathrm{l}$ of PBS supplemented with $10 \%$ fetal bovine serum. Subsequently, $700 \mu \mathrm{l}$ absolute ethanol pre-cooled at $-20^{\circ} \mathrm{C}$ was added to fix the cells for $24 \mathrm{~h}$ at $4^{\circ} \mathrm{C}$. The next day, following centrifugation at $1,000 \mathrm{x} \mathrm{g}$ at room temperature for $5 \mathrm{~min}$, the fixed cells were washed with $1 \mathrm{ml}$ pre-cooled PBS once. Subsequently, the cell pellets were slowly and fully resuspended in $100 \mu 1$ $1 \mathrm{mg} / \mathrm{ml}$ RNase A solution (cat. no. R8020-25; Beijing Solarbio Science \& Technology Co., Ltd.) and incubated in the dark for $30 \mathrm{~min}$ at $37^{\circ} \mathrm{C}$. Finally, the cells were incubated with $400 \mu 150 \mu \mathrm{g} / \mathrm{ml}$ propidium iodide solution in the cell cycle and apoptosis detection kit (cat. no. C001-200; Shanghai Qibao Xintai Biological Technology Co., Ltd., Shanghai, China), which was added to stain the nucleus, for $10 \mathrm{~min}$ in the dark at room temperature. Following staining, the cell cycle status of these cells was detected with a flow cytometer (BD Biosciences; Becton, Dickinson and Company; Accuri C6) and analyzed by FlowJo software 7.6.1v (Tree Star, Inc., Ashland, OR, USA).

Matrigel assay. Prior to inoculation, the 24-well plates and Transwell chambers (cat. no. 3422; Costar; Corning, Inc., Corning, NY, USA) were soaked in PBS for $5 \mathrm{~min}$, and then the chambers were coated with $80 \mu 1$ Matrigel and clotted for $30 \mathrm{~min}$ in an incubator at $37^{\circ} \mathrm{C}$. Following overnight nutrient starvation in serum-free RPMI-1640 medium, the treated cells (H1975 and A549) were trypsinized and inoculated in the upper chamber $\left(5 \times 10^{4}\right.$ cells/well). RPMI-1640 medium with $10 \%$ fetal bovine serum was added to the lower chamber. After $24 \mathrm{~h}$ of incubation, the non-invading cells in the upper chamber were carefully scraped, and the cells that had invaded into the lower chamber were fixed in $4 \%$ formaldehyde (Sinopharm Chemical Reagent Co., Ltd., Shanghai, China) for $10 \mathrm{~min}$ at room temperature, followed by a $30 \mathrm{~min}$ incubation in $0.5 \%$ crystal violet (Beijing Solarbio Science \& Technology Co., Ltd.; C8470) at room temperature. Subsequently, using an upright optical microscope (cat. no. XDS-500C; Shanghai Cai 
A

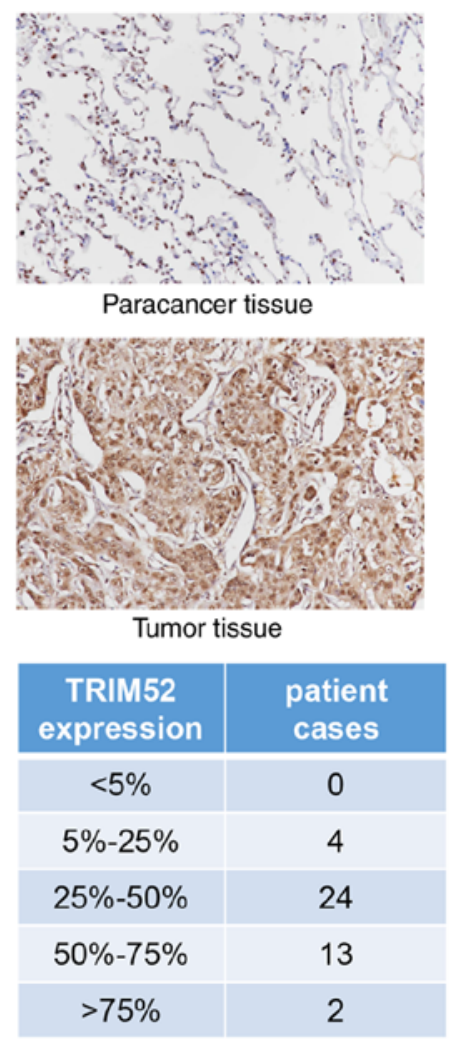

B
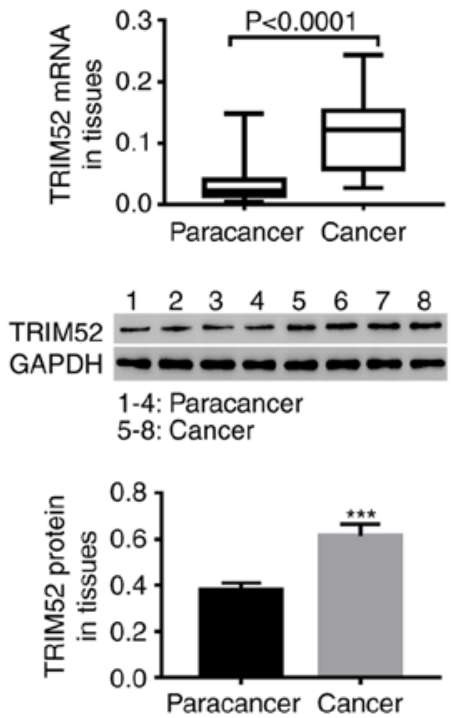

C
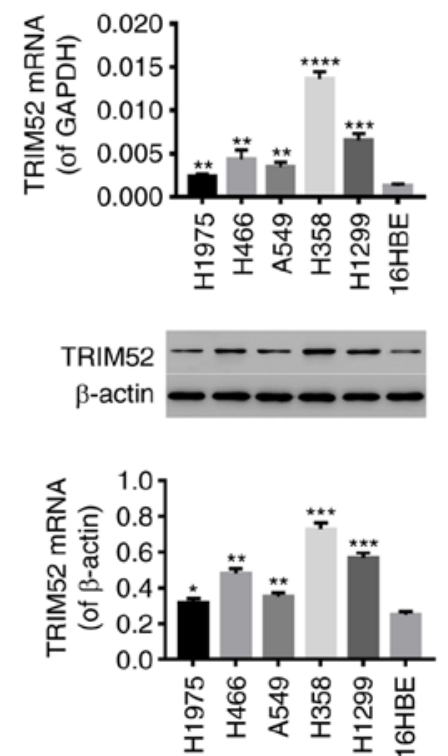

Figure 1. TRIM52 expression is elevated in the tumor tissues of patients with lung cancer and in lung cancer cell lines. A total of 43 pairs of tumor and paracancer tissues were collected from patients with lung cancer. (A) The TRIM52 level in tumor and paracancer tissues was detected by immunohistochemistry. Tissues were imaged under a microscope at a magnification of x200, and a table with all cases grouped according to the overall level of TRIM52 expression is presented. (B) Reverse transcription-quantitative polymerase chain reaction and western blotting were performed to analyze the expression of TRIM52 in tissues. (C) Reverse transcription-quantitative polymerase chain reaction and western blotting were performed to analyze the expression of TRIM52 in five lung cancer cell lines (H1975, H466, A549, H358 and H1299). The data are presented as the mean \pm standard deviation. ${ }^{*} \mathrm{P}<0.05,{ }^{* *} \mathrm{P}<0.01,{ }^{* * * *} \mathrm{P}<0.001$ and ${ }^{* * * *} \mathrm{P}<0.0001$, compared with paracancer tissues or $16 \mathrm{HBE}$ cells. TRIM52, tripartite motif 52 .

Kang Optical Instrument Co., Ltd.), the invading cells were counted in 3 random fields at a magnification of $\mathrm{x} 200$.

Statistical analysis. The statistical analyses of all data in the present study were performed using GraphPad Prism 7.0 software (GraphPad Software, Inc., La Jolla, CA, USA). Student's t-test was used to evaluate the differences between two groups, while one-way analysis of variance followed by Tukey's multiple comparison was performed to evaluate the comparisons among $\geq 3$ groups. Based on at least three independent experiments, quantitative data are shown as the mean \pm standard deviation. $\mathrm{P}<0.05$ was considered to indicate a statistically significant difference.

\section{Results}

TRIM52 expression is elevated in the tumor tissues of patients with lung cancer and in lung cancer cell lines. After 43 pairs of lung tumor and paracancer tissues were collected, immunohistochemistry (Fig. 1A) indicated that compared with the paracancer tissues, the TRIM52 level was notably increased in tumors. All cases were grouped according to the overall level of TRIM52 expression in tissues: $<5 \%$ positivity; $5 \leq \mathrm{n}<25$; $25 \leq \mathrm{n}<50 ; 50 \leq \mathrm{n}<75$; and $\geq 75 \%$. The increased expression of TRIM52 was further demonstrated by RT-qPCR and western blot analysis (Fig. 1B and C). Statistical analysis of the immunohistochemical results demonstrated that high expression of TRIM52 was observed in $97.7 \%$ of tumor tissues (data not shown). Additionally, the TRIM52 mRNA and protein levels in lung cancer cell lines (H1975, H466, A549, H358 and H1299) were significantly increased, compared with pulmonary epithelial cells (16HBE). The TRIM52 levels were increased in H358 and H1299 cells, compared with the other cell lines, while the levels were reduced in H1975 cells (Fig. 1C). These observations indicated that TRIM52 may be involved in the development and progression of lung cancer. A total of 3 lung cancer cell lines (H358, H1299 and $\mathrm{H} 1975)$ were therefore selected for the following experiments.

Down- and upregulation of TRIM52 in lung cancer cell lines. To investigate the effect of TRIM52, shTRIM52 and oeTRIM52 lentiviral vectors were used to regulate the TRIM52 level in lung cancer cell lines. As depicted in Fig. 2, the levels of TRIM52 mRNA and protein were significantly downregulated by shTRIM52 infection in H358 (Fig. 2A) and H1299 (Fig. 2B) cells, and the effects of shTRIM52-1 and shTRIM52-4 were more notable. Furthermore, the TRIM52 level in H1975 cells was significantly upregulated by oeTRIM52 (Fig. 2C). Therefore, the shTRIM52-1, shTRIM52-4 and oeTRIM52 lentiviral vectors were selected for further study due to their more effective regulation of TRIM52 expression. 
A
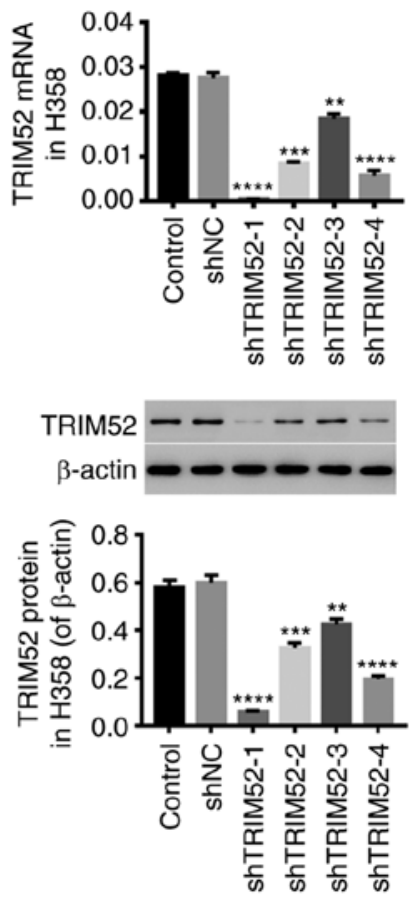

B
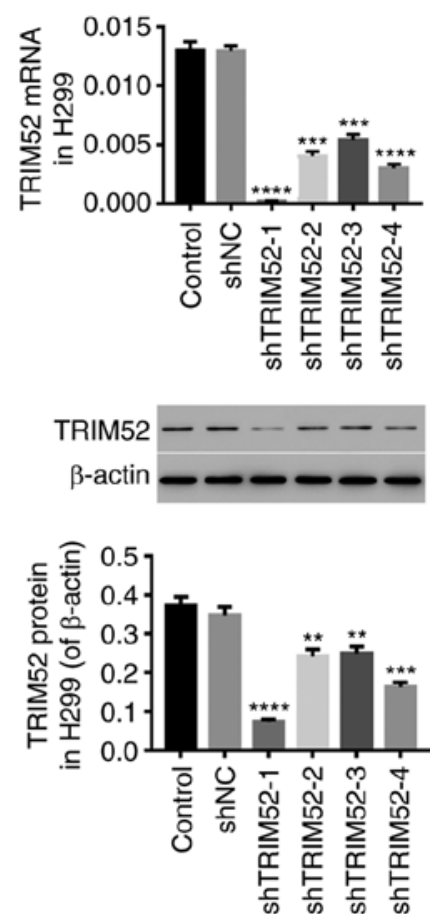
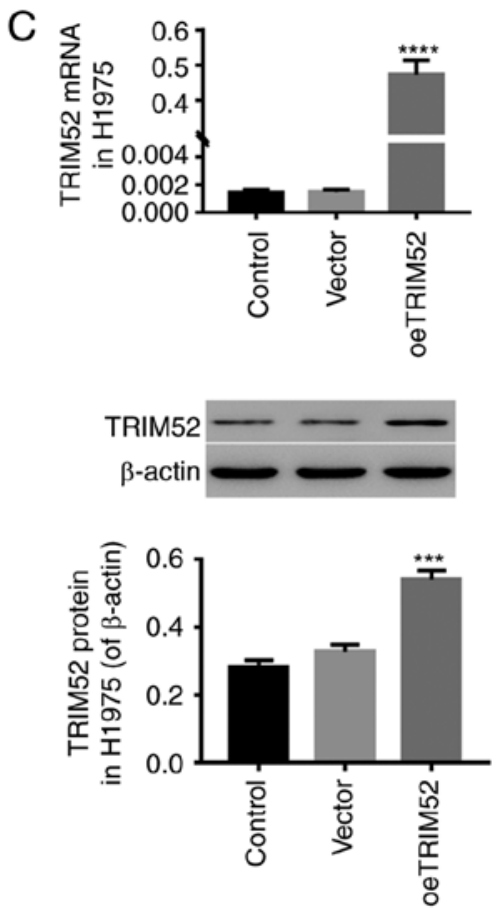

Figure 2. Down- and upregulation of TRIM52 in lung cancer cell lines. Lung cancer cells (H358, H1299 and H1975) were infected with lentiviruses of shNC/shTRIM52 or vector/oeTRIM52, while the cells treated with RPMI-1640 medium served as controls. The total RNA and proteins were extracted from the treated cells after $48 \mathrm{~h}$. (A) TRIM52 mRNA (upper) and protein (lower) levels in TRIM52-slienced H358 cells were detected by reverse transcription-quantitative polymerase chain reaction and western blotting, respectively. (B) Additionally, TRIM52 expression in TRIM52-silenced H1299 cells was also detected. (C) The TRIM52 level in TRIM52-overexpressing H1975 cells was detected. All data are presented as the mean \pm standard deviation. ${ }^{* *} \mathrm{P}<0.01$, ${ }^{* * *} \mathrm{P}<0.001$ and ${ }^{* * *} \mathrm{P}<0.0001$, compared with shNC or vector. TRIM52, tripartite motif 52; NC, control; sh, short hairpin.

Downregulation of TRIM52 inhibits lung cancer cell proliferation by cell cycle arrest. Following downregulation of the TRIM52 level in H358 and H1299 cells, cell proliferation and the cell cycle were evaluated. As depicted in Fig. 3, the proliferation of H358 and H1299 cells was notably inhibited when TRIM52 was downregulated (Fig. 3A). Furthermore, downregulation of TRIM52 significantly arrested the cell cycle at G1 phase in lung cancer cells, which reduced the proportion of cells in S/G2 phase (Fig. 3B). Additionally, the protein levels of $\beta$-catenin, PCNA, c-Myc and Cyclin D1 were significantly decreased in TRIM52-silenced H358 and H1299 cells (Fig. 3C). All results indicated that TRIM52 downregulation exerted an inhibitory effect on the proliferation of lung cancer cells by blocking cell cycle progression possibly via Wnt/ $\beta$-catenin signaling.

TRIM52 regulates cell proliferation, cell cycle progression and invasion through the Wnt/ $\beta$-catenin pathway. Wnt/ $\beta$-catenin signaling activation has been reported to be a critical oncogenic event in the initiation and progression of tumors, and c-Myc and Cyclin D1 are two downstream Wnt/ $\beta$-catenin signaling molecules (35). PCNA, a non-histone nuclear protein that functions in DNA synthesis, is a marker of cell proliferative activity in lung cancer (36) and has important prognostic value $(37,38)$. The application of the $\mathrm{Wnt} / \beta$-catenin inhibitor XAV939 has been reported in numerous studies $(39,40)$. In the present study, the Wnt/ $\beta$-catenin inhibitor XAV-939 was applied for further study. As depicted in Fig. 4, the upregulation of TRIM52 significantly promoted cell proliferation (Fig. 4A) and facilitated the entry of cells into the $S$ phase from the
G1 phase (Fig. 4B), which was concurrent with increases in $\beta$-catenin, PCNA, c-Myc and Cyclin D1 expression (Fig. 4C). The upregulation of TRIM52 in normal epithelial 16HBE cells also induced cell proliferation and S-phase progression. Furthermore, the invasiveness of H1975 and A549 cells was significantly increased by TRIM52 upregulation (Fig. 4D). In contrast, treatment with XAV-939 completely counteracted the effect of TRIM52 upregulation in lung cancer cells, and a rescue effect of TRIM52 upregulation was observed upon Wnt $/ \beta$-catenin inhibition. It has been reported that the activation of Wnt/ $\beta$-catenin signaling is frequently observed in lung cancer and that it promotes the proliferation of lung cancer cells $(11,41)$, which is consistent with the present results. These results further demonstrated that TRIM52 regulates the proliferation and invasiveness of lung cancer cells possibly through regulation of $\mathrm{Wnt} / \beta$-catenin pathway activation.

\section{Discussion}

Increasing evidence demonstrates that TRIM proteins, including TRIM29 (42), TRIM16 (43) and TRIM15 (44), are of great importance in the development and progression of cancer. TRIM proteins were revealed to be involved in the regulation of various cellular processes, including cell proliferation, in cancer (45). A previous study indicated that TRIM59 is overexpressed in NSCLC, and promotes the proliferation and migration of NSCLC cells (46). In the present study, it was determined that TRIM52 was elevated in tumor tissues of patients with lung cancer and in tumor cell lines, which indicates that TRIM52 may act as an 

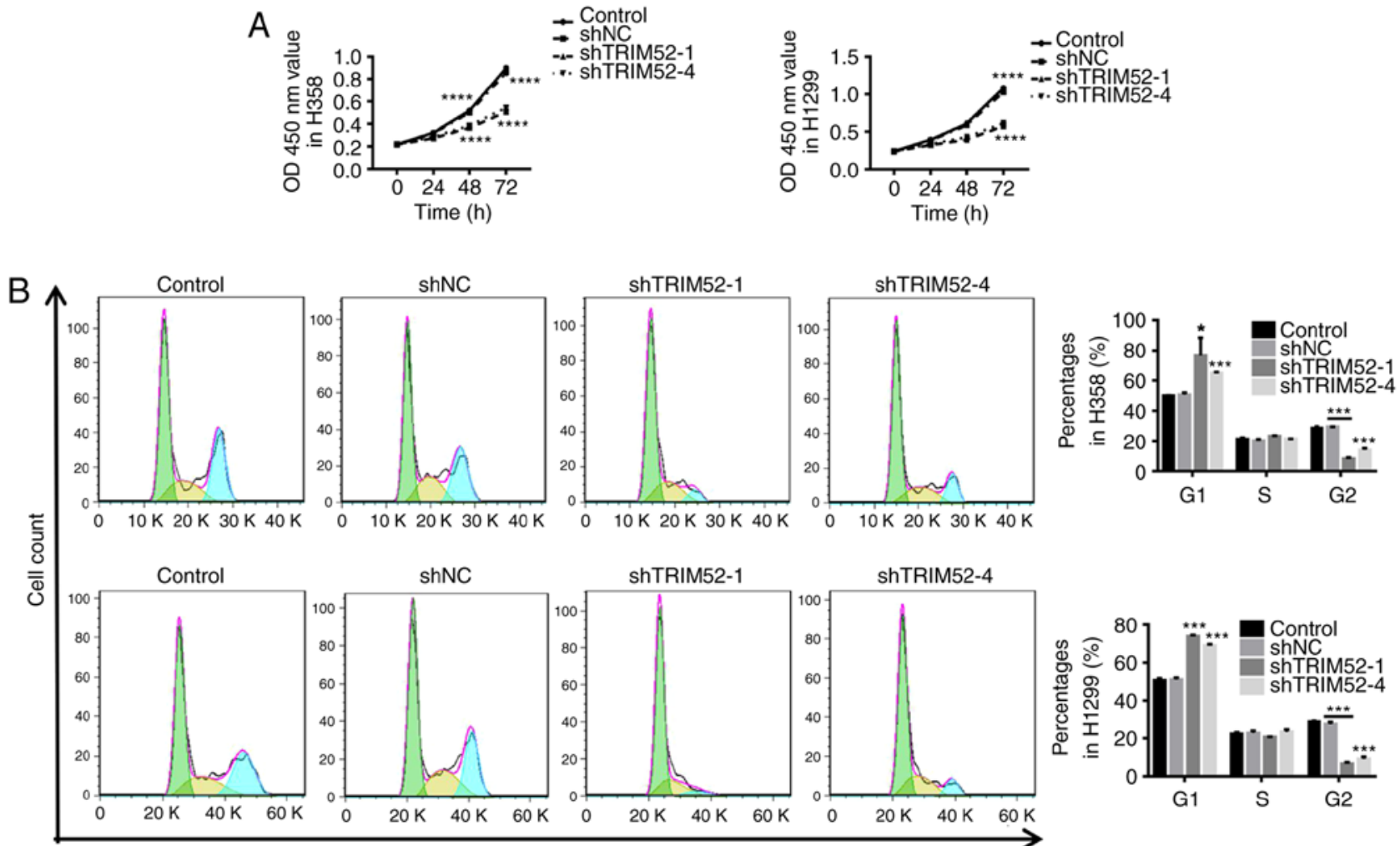

DNA content
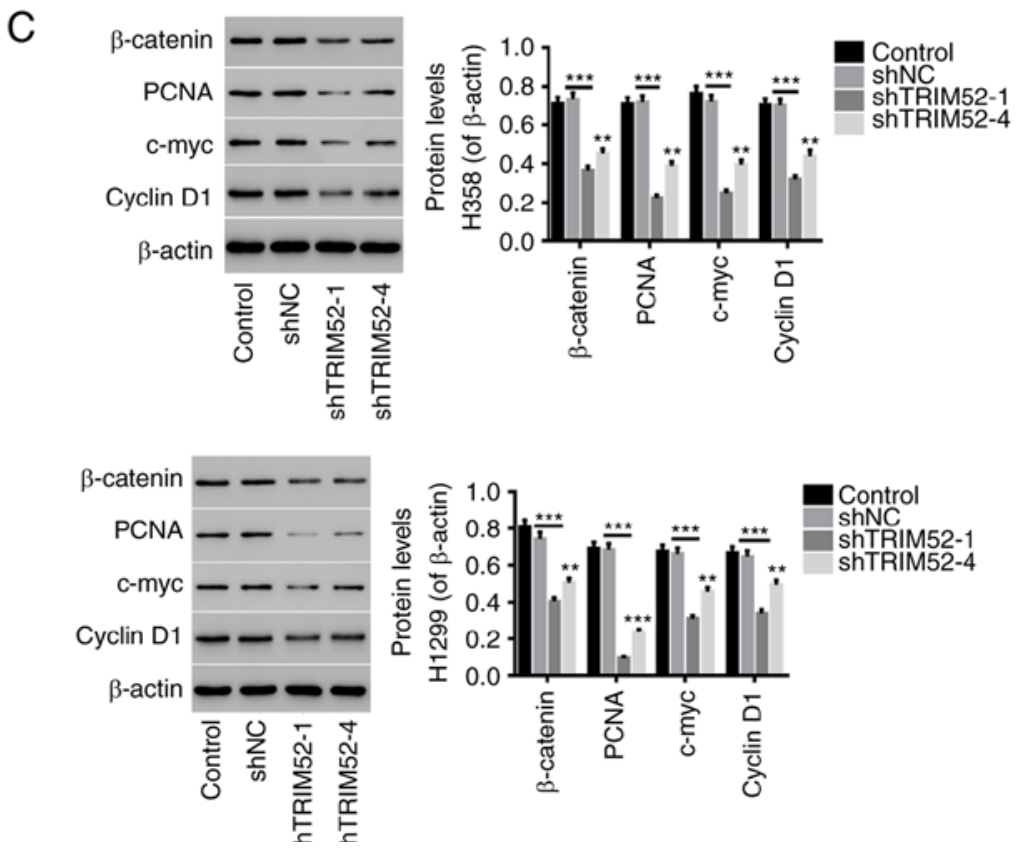

Figure 3. Downregulation of TRIM52 inhibits lung cancer cell proliferation via cell cycle arrest. Lung cancer cells (H358 and H1299) were infected with shNC/shTRIM52 lentiviruses, while the cells treated with RPMI-1640 medium served as controls. (A) The proliferation of TRIM52-slienced H358 and H1299 cells was determined at 0,24, 48 and $72 \mathrm{~h}$ with a Cell Counting Kit-8 assay. (B) Subsequently, $48 \mathrm{~h}$ after infection, the cell cycle was detected by flow cytometry. (C) The protein levels of $\beta$-catenin, PCNA, c-Myc and Cyclin D1 were quantified by western blotting. Data are presented as the mean \pm standard deviation. ${ }^{* *} \mathrm{P}<0.01,{ }^{* * * *} \mathrm{P}<0.001$ and ${ }^{* * * *} \mathrm{P}<0.0001$, compared with shNC. TRIM52, tripartite motif 52; NC, control; sh, short hairpin; PCNA, proliferating cell nuclear antigen.

oncogene in lung cancer. The downregulation of TRIM52 in lung cancer cells significantly inhibited cell proliferation by arresting cell cycle progression, and TRIM52 upregulation promoted proliferation and invasion. Notably, recent genomic analysis indicated that in certain genetic cancer cell backgrounds, an appropriate expression of TRIM52 may be essential for efficient proliferation and survival of certain cancer cell lines $(47,48)$, which are in agreement with the present data. This indicates that the inhibitory effect of TRIM52 downregulation on the proliferation of lung cancer cells may contribute to novel treatments for lung cancer. 

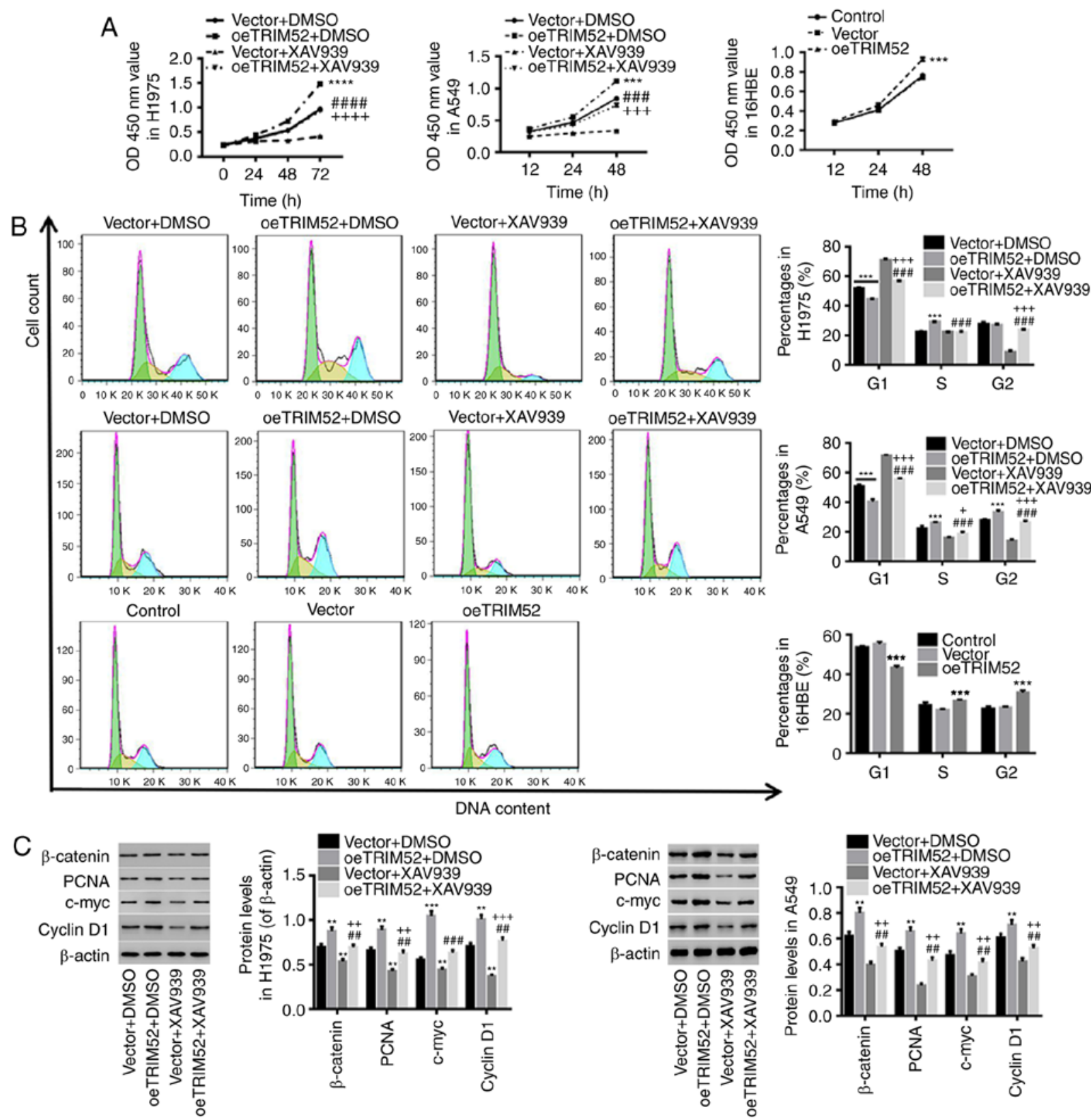

Figure 4. TRIM52 regulates proliferation, cell cycle and invasion through the Wnt/ $\beta$-catenin pathway. H1975 and A549 cells were treated with vector/oeTRIM52 lentiviruses and $20 \mu \mathrm{M} \mathrm{XAV939} \mathrm{(Wnt/} \beta$-catenin inhibitor), and 16HBE cells were treated with vector/oeTRIM52 lentiviruses. RPMI-1640 medium-treated cells served as controls. (A) The proliferation of treated-H1975, A549 and 16HBE cells was assessed with a Cell Counting Kit-8 assay. (B) Using flow cytometry, the cell cycle was evaluated after 48 h. (C) The levels of $\beta$-catenin, PCNA, c-Myc and Cyclin D1 proteins were also detected.

Furthermore, it was also investigated the mechanism that underlies TRIM52 in the regulation of lung cancer cell proliferation and invasion. It has been reported that aberrant activation of the $\mathrm{Wnt} / \beta$-catenin pathway is associated with the development and progression of cancer (49-51). Control of $\mathrm{Wnt} / \beta$-catenin signaling by disheveled binding antagonist of $\beta$-catenin 3 has potential as a therapeutic strategy for colorectal cancer (52). The proto-oncogene c-Myc has been reported to serve a primary role in the biological processes of tumors, including growth and apoptosis (53). When it forms a complex with its partner kinases, including cyclin dependent kinase 4 (CDK4) and CDK6, Cyclin D1, which is overexpressed in a variety of human cancer types, including breast and colon carcinoma cancer $(16,54,55)$, allows cells to proceed into the S phase (56). Compared with Cyclin D1, PCNA has been reported to be elevated in the late G1 and $S$ phases of the cell cycle (57-59). Additionally, in the present study, TRIM52-induced cell proliferation and S-phase cell cycle progression were counteracted by the $\beta$-catenin inhibitor XAV939. This was concurrent with decreased expression of $\beta$-catenin, PCNA, c-Myc and Cyclin D1 proteins, and a rescue effect of TRIM52 upregulation on Wnt/ $\beta$-catenin inhibition. These observations are in agreement with those of previous reports, in that TRIM52 ablation increases the proportion of cells in the G0/G1-phase $(30,31,60)$, which reveals that TRIM52 may regulate lung cancer cell proliferation through activation of the Wnt/ $\beta$-catenin signaling pathway. 


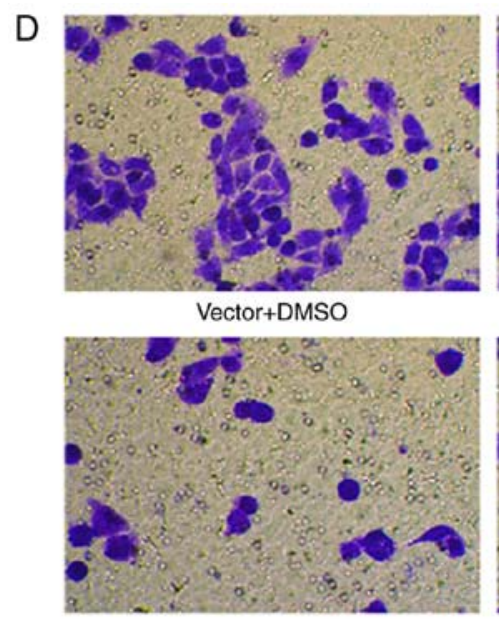

Vector+XAV939

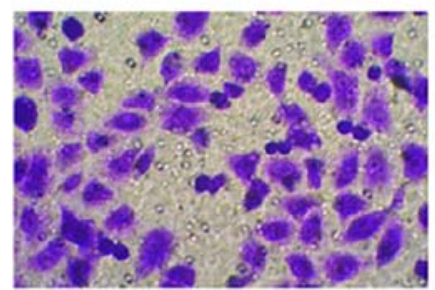

Vector+DMSO

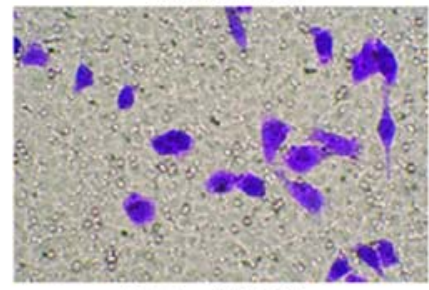

Vector+XAV939

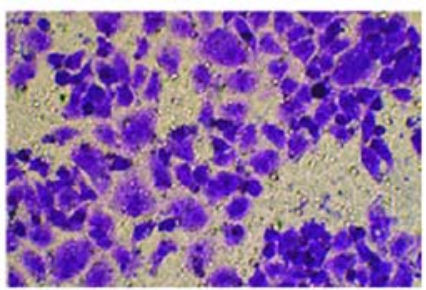

oeTRIM52+DMSO

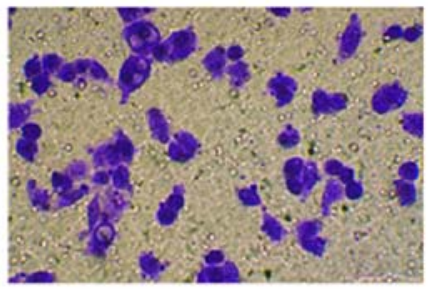

oeTRIM52+XAV939

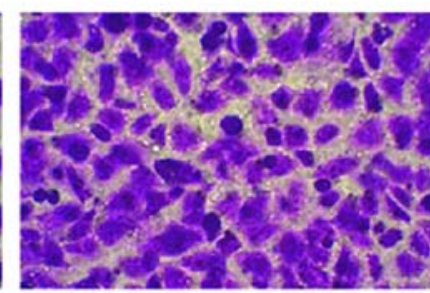

oeTRIM52+DMSO

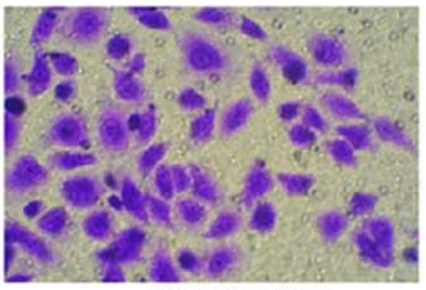

oeTRIM52+XAV939
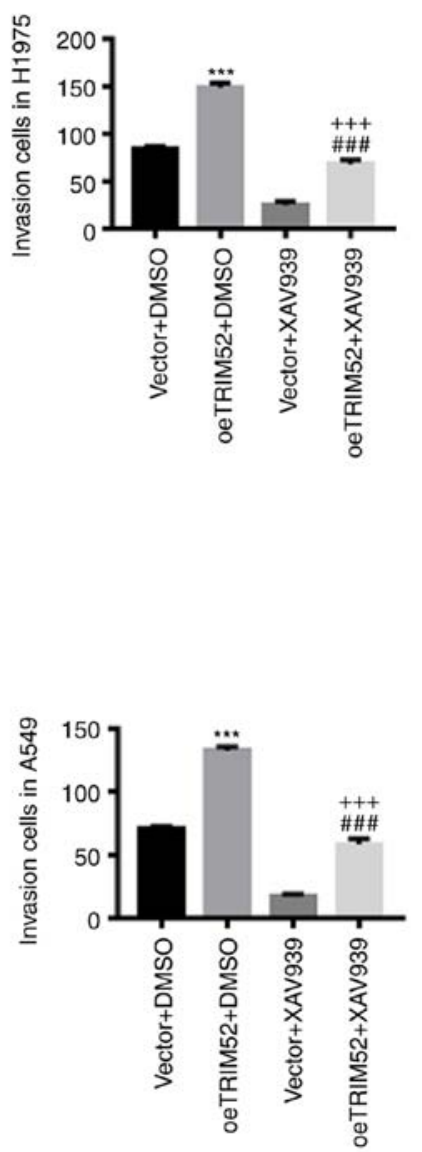

Figure 4. Continued. (D) Invasiveness of H1975 and A549 cells was determined with a Matrigel assay. Data are expressed as the mean \pm standard deviation.

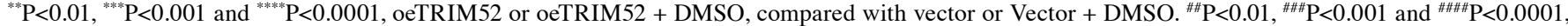
oeTRIM52 + XAV939, compared with oeTRIM52 + DMSO. ${ }^{+} \mathrm{P}<0.05,{ }^{++} \mathrm{P}<0.01,{ }^{+++} \mathrm{P}<0.001$ and ${ }^{+++} \mathrm{P}<0.0001$, oeTRIM52 + XAV939, compared with vector + XAV939. TRIM52, tripartite motif 52; DMSO, dimethyl sulfoxide; PCNA, proliferating cell nuclear antigen.

In summary, it was demonstrated that TRIM52 may act as an oncogene in lung cancer progression. The downregulation of TRIM52 significantly suppressed lung cancer cell proliferation via blocking cell cycle progression, and TRIM52 upregulation promoted proliferation and invasion, which may have occurred through activation of $\mathrm{Wnt} / \beta$-catenin signaling. Therefore, targeting TRIM52 is a potential therapeutic strategy for the treatment of lung cancer.

\section{Acknowledgements}

Not applicable.

\section{Funding}

The present study was funded by National Thirteenth Five-Year Science and Technology Major Special Project for New Drug Innovation and Development: The construction of a demonstration technology platform for the clinical evaluation of new drugs for malignant tumor and other diseases (grant no. 201 7ZX09304001), and Shanghai municipal health and Family
Planning Commission: The inhibition effects of Jinfukang Oral Solution on lung cancer through TRIM52-Wnt/ $\beta$-catenin pathway (grant no. 20174Y0053).

\section{Availability of data and materials}

All data generated or analyzed during this study are included in this published article.

\section{Authors' contributions}

XM and HL conceived and designed the study. XM, LZ and WX performed the experiments. XM and HL wrote the manuscript. All authors read and approved the final manuscript.

\section{Ethics approval and consent to participate}

All experiments conducted in this study were approved by the Ethics Committee of Shanghai University of Traditional Chinese Medicine and written informed consent was obtained. 


\section{Patient consent for publication}

Not applicable.

\section{Competing interests}

The authors declare that they have no competing interests.

\section{References}

1. Ferlay J, Shin H, Bray F, Forman D, Mathers C and Parkin D: GLOBOCAN, 2008 V1. 2, cancer incidence and mortality Worldwide: IARC Cancer Base No. 10. 2010.

2. Bray F, Jemal A, Grey N, Ferlay J and Forman D: Global cancer transitions according to the Human Development Index (2008-2030): A population-based study. Lancet Oncol 13: 790-801, 2012.

3. Jemal A, Bray F, Center MM, Ferlay J, Ward E and Forman D: Global cancer statistics. Ca Cancer J Clin 61: 69-90, 2011.

4. Herbst RS, Heymach JV and Lippman SM: Lung cancer. N Engl J Med 359: 1367-1380, 2008.

5. Blandin Knight S, Crosbie PA, Balata H, Chudziak J, Hussell T and Dive C: Progress and prospects of early detection in lung cancer. Open Biol 7: pii: 170070, 2017.

6. National Center for Chronic Disease Prevention and Health Promotion (US) Office on Smoking and Health: The health consequences of Smoking-50 years of progress: A report of the surgeon general. Atlanta (GA), Centers for Disease Control and Prevention (US), 2014.

7. Stockwell HG, Goldman AL, Lyman GH, Noss CI, Armstrong AW, Pinkham PA, Candelora EC and Brusa MR: Enviromental tobacco smoke and lung cancer risk in nonsmoking women. J Natl Cancer Inst 84: 1417-1422, 1992.

8. Boffetta P, Agudo A, Ahrens W, Benhamou E, Benhamou S, Darby SC, Ferro G, Fortes C, Gonzalez CA, Jöckel KH, et al Multicenter case-control study of exposure to environmental tobacco smoke and lung cancer in europe. J Natl Cancer Inst 90 $1440-1450,1998$

9. Kiyohara C, Wakai K, Mikami H, Sido K, Ando M and Ohno Y: Risk modification by CYP1A1 and GSTM1 polymorphisms in the association of environmental tobacco smoke and lung cancer: A case-control study in Japanese nonsmoking women. Int J Cancer 107: 139-144, 2003.

10. Nana-Sinkam SP and Powell CA: Molecular biology of lung cancer: Diagnosis and management of lung cancer, 3rd edition: American College of Chest Physicians evidence-based clinical practice guidelines. Chest 143 (5 Suppl): e30S-e39S, 2013.

11. Nguyen DX, Chiang AC, Zhang HF, Kim JY, Kris MG, Ladanyi M, Gerald WL and Massagué J: WNT/TCF Signaling through LEF1 and HOXB9 mediates lung adenocarcinoma metastasis. Cell 138: 51-62, 2009.

12. Chen G, Shukeir N, Potti A, Sircar K, Aprikian A, Goltzman D and Rabbani SA: Up-regulation of Wnt-1 and beta-catenin production in patients with advanced metastatic prostate carcinoma: Potential pathogenetic and prognostic implications. Cancer 101: 1345-1356, 2004.

13. Zhang WM, Lo Muzio L, Rubini C and Yan G: Effect of WNT-1 on beta-catenin expression and its relation to Ki-67 and tumor differentiation in oral squamous cell carcinoma. Oncol Rep 13: 1095-1099, 2005.

14. Xu X, Sun PL, Li JZ, Jheon S, Lee CT and Chung JH: Aberrant Wnt $1 / \beta$-catenin expression is an independent poor prognostic marker of non-small cell lung cancer after surgery. $\mathrm{J}$ Thorac Oncol 6: 716-724, 2011.

15. He TC, Sparks AB, Rago C, Hermeking H, Zawel L, da Costa LT, Morin PJ, Vogelstein B and Kinzler KW: Identification of c-MYC as a target of the APC pathway. Science 281: 1509-1512, 1998.

16. Tetsu O and Mccormick F: Beta-catenin regulates expression of Cyclin D1 in colon carcinoma cells. Nature 398: 422-426, 1999.

17. Hatakeyama S: TRIM family proteins: Roles in autophagy, immunity, and carcinogenesis. Trends Biochem Sci 42: 297-311, 2017.

18. Reymond A, Meroni G, Fantozzi A, Merla G, Cairo S, Luzi L, Riganelli D, Zanaria E, Messali S, Cainarca S, et al: The tripartite motif family identifies cell compartments. EMBO J 20: $2140-2151,2001$
19. Mallery DL, McEwan WA , Bidgood SR, Towers GJ, Johnson CM and James LC: Antibodies mediate intracellular immunity through tripartite motif-containing 21 (TRIM21). Proc Nat Acad Sci USA 107: 19985-19990, 2010.

20. Jiang T, Tang HM, Lu S, Yan DW, Yang YX and Peng ZH Up-regulation of tripartite motif-containing 29 promotes cancer cell proliferation and predicts poor survival in colorectal cancer. Med Oncol 30: 715, 2013.

21. Ren H, Xu Y, Wang Q, Jiang J, Wudumuli, Hui L, Zhang Q, Zhang X, Wang E, Sun L and Qiu X: E3 ubiquitin ligase tripartite motif-containing 71 promotes the proliferation of non-small cell lung cancer through the inhibitor of kappaB- $\alpha /$ nuclear factor kappaB pathway. Oncotarget 9: 10880-10890, 2017.

22. Yamada Y, Takayama KI, Fujimura T, Ashikari D, Obinata D, Takahashi S, Ikeda K, Kakutani S, Urano T, Fukuhara H, et al: A novel prognostic factor TRIM44 promotes cell proliferation and migration, and inhibits apoptosis in testicular germ cell tumor. Cancer Sci 108: 32-41, 2016.

23. Zhang Z, Xu C, Zhang X, Huang L, Zheng C, Chen H, Wang Y, Ju H and Yao Q: TRIM11 upregulation contributes to proliferation, invasion, and EMT of hepatocellular carcinoma cells. Oncol Res 25: 691-699, 2017.

24. Dükel M, Streitfeld WS, Tang TCC, Backman LR, Ai L, May WS and Brown KD: The breast cancer tumor suppressor TRIM29 is expressed via ATM-dependent signaling in response to hypoxia. J Biol Chem 291: 21541-21552, 2016.

25. Groner AC, Cato L, de Tribolet-Hardy J, Bernasocchi T, Janouskova H, Melchers D, Houtman R, Cato ACB, Tschopp P, $\mathrm{Gu}$ L, et al: TRIM24 is an oncogenic transcriptional activator in prostate cancer. Cancer Cell 29: 846-858, 2016.

26. Li Y, Ma C, Zhou T, Liu Y, Sun L and Yu Z: TRIM65 negatively regulates p53 through ubiquitination. Biochem Biophys Res Commun 473: 278-282, 2016

27. Wang XL, Shi WP, Shi HC, Lu SC, Wang K, Sun C, He JS, Jin WG, Lv XX, Zou H, et al: Knockdown of TRIM65 inhibits lung cancer cell proliferation, migration and invasion: A therapeutic target in human lung cancer. Oncotarget 7: 81527-81540, 2016.

28. Li H, Zhang Y, Zhang Y, Bai X, Peng Y and He P: TRIM31 is downregulated in non-small cell lung cancer and serves as a potential tumor suppressor. Tumour Biol 35: 5747-5752, 2014.

29. Malfavon-Borja R, Sawyer SL, Wu LI, Emerman M and Malik HS: An evolutionary screen highlights canonical and noncanonical candidate antiviral genes within the primate TRIM gene family. Genome Biol Evol 5: 2141-2154, 2013.

30. Zhang Y, Wu SS, Chen XH, Tang ZH, Yu YS and Zang GQ: Tripartite motif containing 52 (TRIM52) promotes cell proliferation in hepatitis B virus-associated hepatocellular carcinoma. Med Sci Monit 23: 5202-5210, 2017.

31. Zhang Y, Tao R, Wu SS, Xu CC, Wang JL, Chen J, Yu YS, Tang ZH, Chen XH and Zang GQ: TRIM52 up-regulation in hepatocellular carcinoma cells promotes proliferation, migration and invasion through the ubiquitination of PPM1A. J Exp Clin Cancer Res 37: 116, 2018.

32. Yang W, Liu L, Li C, Luo N, Chen R, Li L, Yu F and Cheng Z: TRIM52 plays an oncogenic role in ovarian cancer associated with NF- $\mathrm{kB}$ pathway. Cell Death Dis 9: 908, 2018.

33. Livak KJ and Schmittgen TD: Analysis of relative gene expression data using real-time quantitative PCR and the $2^{-\triangle \Delta C T}$ method. Methods 25: 402-408, 2001.

34. Hong J, Kang B, Kim A, Hwang S, Ahn J, Lee S, Kim J, Park JH and Cheon DS: Development of a highly sensitive real-time one step RT-PCR combined complementary locked primer technology and conjugated minor groove binder probe. Virol $\mathrm{J} 8$ : $330,2011$.

35. Vogelstein B and Kinzler KW: Cancer genes and the pathways they control. Nat Med 10: 789-799, 2004.

36. Nguyen VN, Mirejovský P, Mirejovský T, Melínová L and Mandys V: Expression of Cyclin D1, Ki-67 and PCNA in non-small cell lung cancer: Prognostic significance and comparison with p53 and bcl-2. Acta Histochem 102: 323-338, 2000

37. Woods AL, Hall PA, Shepherd NA, Hanby AM, Waseem NH, Lane DP and Levison DA: The assessment of proliferating cell nuclear antigen (PCNA)immunostaining in primary gastrointestinal lymphomas and its relationship to histological grade, $\mathrm{S}+\mathrm{G}_{2}+\mathrm{M}$ phase fraction (flow cytometric analysis) and prognosis. Histopathology 41: 165-171, 2002. 
38. Yu CC, Hall PA, Fletcher CD, Camplejohn RS, Waseem NH, Lane DP and Levison DA: Haemangiopericytomas: The prognostic value of immunohistochemical staining with a monoclonal antibody to proliferating cell nuclear antigen (PCNA). Histopathology 19: 29-33, 1991.

39. Tian XH, Hou WJ, Fang Y, Fan J, Tong H, Bai SL, Chen Q, Xu H and Li Y: XAV939, a tankyrase 1 inhibitior, promotes cell apoptosis in neuroblastoma cell lines by inhibiting Wnt/ $\beta$-catenin signaling pathway. J Exp Clin Cancer Res 32: 100, 2013.

40. Lu P, Wang Y, Liu X, Wang H, Zhang X, Wang K, Wang Q and $\mathrm{Hu}$ R: Malignant gliomas induce and exploit astrocytic mesenchymal-like transition by activating canonical Wnt/ $\beta$-catenin signaling. Med Oncol 33: 66, 2016.

41. Lim JH, Park JW and Chun YS: Human arrest defective 1 acetylates and activates beta-catenin, promoting lung cancer cell proliferation. Cancer Res 66: 10677-10682, 2006.

42. Rui X, Hu J, Zhang T, Chao J and Wang HY: TRIM29 overexpression is associated with poor prognosis and promotes tumor progression by activating Wnt/ $\beta$-catenin pathway in cervical cancer. Oncotarget 7: 28579-28591, 2016.

43. Kim PY, Tan O, Liu B, Trahair T, Liu T, Haber M, Norris MD, Marshall GM and Cheung BB: High TDP43 expression is required for TRIM16-induced inhibition of cancer cell growth and correlated with good prognosis of neuroblastoma and breast cancer patients. Cancer Lett 374: 315-323, 2016.

44. Lee OH, Lee J, Lee KH, Woo YM, Kang JH, Yoon HG, Bae SK, Songyang Z, Oh SH and Choi Y: Role of the focal adhesion protein TRIM15 in colon cancer development. Biochim Biophys Acta 1853: 409-421, 2015.

45. Watanabe M and Hatakeyama S: TRIM proteins and diseases J Biochem 161: 135-144, 2017

46. Zhan W, Han T, Zhang C, Xie C, Gan M, Deng K, Fu M and Wang JB: TRIM59 promotes the proliferation and migration of non-small cell lung cancer cells by upregulating cell cycle related proteins. PLoS One 10: e0142596, 2015.

47. Hart T, Chandrashekhar M, Aregger M, Steinhart Z, Brown KR, Macleod G, Mis M, Zimmermann M, Fradet-Turcotte A, Sun S, et al: High-resolution CRISPR screens reveal fitness genes and genotype-specific cancer liabilities. Cell 163: 1515-1526, 2015.

48. Wang T, Birsoy K, Hughes NW, Krupczak KM, Post Y, Wei JJ, Lander ES and Sabatini DM: Identification and characterization of essential genes in the human genome. Science 350: 1096-1101, 2015.
49. Peifer $M$ and Polakis P: Wnt signaling in oncogenesis and embryogenesis-a look outside the nucleus. Science 287: 1606-1609, 2000

50. You Z, Saims D, Chen S, Zhang Z, Guttridge DC, Guan K, Macdougald OA, Brown AM, Evan G, Kitajewski J and Wang CY: Wnt signaling promotes oncogenic transformation by inhibiting c-Myc-induced apoptosis. J Cell Biol 157: 429-440, 2002.

51. Brown AM: Wnt signaling in breast cancer: Have we come full circle? Breast Cancer Res 3: 351-355, 2001.

52. Jiang X, Tan J, Li J, Kivimäe S, Yang X, Zhuang L, Lee PL, Chan MT, Stanton LW, Liu ET, et al: DACT3 is an epigenetic regulator of Wnt/beta-catenin signaling in colorectal cancer and is a therapeutic target of histone modifications. Cancer Cell 13: 529-541, 2008

53. Miller DM, Thomas SD, Islam A, Muench D and Sedoris K: c-Myc and cancer metabolism. Clin Cancer Res 18: 5546-5553, 2012.

54. Hall M and Peters G: Genetic alterations of cyclins, cyclin-dependent kinases, and Cdk inhibitors in human cancer. Adv Cancer Res 68: 67-108, 1996.

55. Yu Q, Geng Y and Sicinski P: Specific protection against breast cancers by Cyclin D1 ablation. Nature 411: 1017-1021, 2001.

56. Lukas J, Bartkova J, Rohde M, Strauss M and Bartek J: Cyclin D1 is dispensable for G1 control in retinoblastoma gene-deficient cells independently of cdk4 activity. Mol Cell Biol 15: 2600-2611, 1995.

57. Griffey SM, Kraegel SA and Madewell BR: Proliferation indices in spontaneous canine lung cancer: Proliferating cell nuclear antigen (PCNA), Ki-67 (MIB1) and mitotic counts. J Comp Pathol 120: 321-332, 1999.

58. Celis JE and Celis A: Cell cycle-dependent variations in the distribution of the nuclear protein cyclin proliferating cell nuclear antigen in cultured cells: Subdivision of S phase. Proc Natl Acad Sci USA 82: 3262-3266, 1985.

59. Bravo R, Frank R, Blundell PA and Macdonaldbravo $\mathrm{H}$ Cyclin/PCNA is the auxiliary protein of DNA polymerase-delta. Nature 326: 515-517, 1987.

60. Benke S, Agerer B, Haas L, Stöger M, Lercher A, Gabler L, Kiss I, Scinicariello S, Berger W, Bergthaler A, et al: Human tripartite motif protein 52 is required for cell context-dependent proliferation. Oncotarget 9: 13565-13581, 2018. 